described for agenesis of the corpus callosum as seen on ventriculography ${ }^{2}$ and CT scanning ${ }^{3}$ can be seen in the present case on ultrasound scanning, with the exception of dilatation of the 3rd ventricle and its interposition between the lateral ventricles. This was not found on the CT scans of the present case either. The degree of dilatation and interposition of the 3rd ventricle is said to be variable ${ }^{3}$ and absence of this finding may mean that the agenesis is incomplete. ${ }^{2}$

Although rare, agenesis of the corpus callosum should be easily recognisable on neonatal ultrasound head scanning.

I thank Dr E M O'Neill, for permission to report this case and Dr I Holland, General Infirmary, Leeds, for the CT scans.
This work was supported by the H F Hawley Trust.

\section{References}

1 Smith D W. Recognizable patterns of human malformation, second edition. Philadelphia: Saunders, 1976: 18-9.

2 Caffey J. Pediatric x-ray diagnosis, fifth edition. Chicago: YB Medical Publishers, 1967: 158-61.

3 Byrd S E, Harwood-Nash D C, Fitz C R. Absence of the corpus callosum: computed tomographic evaluation in infants and children. J Can Assoc Radiol 1978; 29: 108-12.

Correspondence to Dr F Sheehy Skeffington, H F Hawley Perinatal Research Fellow, c/o Ward 10, Barnsley District General Hospital, Gawber Road, Barnsley S75 2EP, Yorkshire.

Received 22 March 1982

\title{
Controlled trial of imipramine in diurnal enuresis
}

\author{
ROY MEADOW AND IAN BERG \\ Department of Paediatrics and Child Health, St James's University Hospital, Leeds
}

SUMMARY Twenty-seven children with diurnal enuresis were studied in a double-blind randomised controlled trial of imipramine. Outcome was not related to such features as age, gender, maximum functional bladder capacity, or evidence of psychiatric disturbance. Although the condition in several children improved, no evidence emerged to suggest that imipramine was superior to placebo in the treatment of the condition.

Day wetting is a troublesome problem which not uncommonly affects children of school age, especially those who wet the bed. The characteristic features of this diurnal form of enuresis have been described elsewhere. ${ }^{12}$ Unfortunately, no effective method of treating wetting, which occurs during the day when the child is up and about, has so far been found. ${ }^{3}$ Imipramine is a drug which relieves bed wetting, at least temporarily. ${ }^{4}$

It was therefore decided to carry out a trial of imipramine in persistent day wetters to see if diurnal enuresis could be lessened.

\section{Procedure}

Children treated at the paediatric outpatient department of a large undergraduate teaching hospital were studied. In each instance a history was taken, a physical examination was carried out, and a midstream specimen of urine was examined. No other special investigations were done routinely. However, since the presence of a urinary tract infection is considered to justify radiological investigation, over half the children had an intravenous urogram and a voiding cystourethrogram. Any urine infection was eradicated before the child was included in the study. During the trial, the urine was checked regularly and kept free from infection. Any child over age 5 years whose daytime wetting was a substantial problem was taken into the trial until it comprised 27 children. Although several also had some bed wetting the main cause of parental concern was the day wetting.

All the mothers completed an Eysenck personality inventory for themselves, and a Rutter A Questionnaire concerned with their children's behaviour. Each was asked to give permission so that the child's school could be visited and the form teacher could complete a Rutter B Questionnaire and a Conners Teachers Questionnaire.

At the first visit to the outpatient department initial clinical assessment included estimation of the maximum functional bladder capacity. Each mother was given a chart to record wetting events during the next 4 weeks before any treatment was started.

On the second visit, it was decided whether the child's wetting was sufficiently troublesome to warrant drug treatment. If so, allocation to the imipramine or the placebo group was made by 
opening the next in a series of envelopes containing randomly distributed assignments. Tofranil syrup $(25 \mathrm{mg})$ was given every morning for 4 weeks and $50 \mathrm{mg}$ for the next 4 weeks to those on the drug. The dosage of the placebo syrup was correspondingly doubled. The maximum functional bladder capacity was measured after 4 weeks on the smaller dose and after 4 weeks on the larger dose. There was a followup visit after 6 months. Charting of daytime wetting was continued throughout. Two ratings were made. Firstly, the number of completely dry days in a 4-week period-the 'dryness' score-out of a possible maximum of 28. Secondly, an estimate of the severity of wetting, none (0); 'slight' (1) dampening of the pants, insufficient to penetrate outer clothing; 'moderate' (2) sodden pants, with wet patch on outer clothing; 'severe' (3) puddles on seat or floor. A 'wetness' score, out of a possible maximum of 84 over 4 weeks was the sum of the daily scores.

\section{Results}

There were 9 boys and 18 girls in the trial. The average age was 8 years $(S D \pm 2)$. Clinical assessments were completed in 26 and school forms were completed in 23 .

Less wetting occurred during the trial period than before, but no significant differences $(P>0.05)$ emerged using analysis of variance when the drug $(n=14)$ and placebo $(n=13)$ groups were compared, looking at wetness and dryness scores before treatment, on the smaller dose, on the larger dose, and on the follow-up (Table).

The drug and placebo groups did not differ significantly on the Rutter A Scale, the Conners Teachers Questionnaire, or on the Eysenck personality inventory. The placebo group had significantly high $T(11.5$ versus 5.0$)$ and $A(3.6$ versus 0.4$)$ scores on the Rutter B Questionnaire $(P<0 \cdot 05)$.

Analyses of covariance were carried out using wetness and dryness scores as dependent variables. Differences in values on the smaller compared with the larger doses and those before starting treatment were looked at, taking into consideration age, gender, Rutter A T score, Rutter B P score, and the mother's Eysenck personality inventory $\mathrm{N}$ score.
There were no significant differences between drug and placebo groups.

Maximum functional bladder capacities were small (mean $174 \mathrm{ml}$ ) in the sample but did not differ between the drug and placebo groups, before starting treatment, or between the smaller and the larger dose. There was no significant change in maximum functional bladder capacity with treatment $(P>0.05)$.

A comparison between day wetting children $(n=23)$ and the same number of controls from their class at school showed no significant differences in age (mean 8.3 years in each group) or gender ( 8 boys and 15 girls in each group). Scores on the Rutter B T scale were significantly higher in the day wetting children (mean $=7 \cdot 6$ ) compared with the controls (mean 2.7, F $=9 \cdot 3, \mathrm{P}<0.01$ ). All 5 of the Conners Teachers Questionnaire factors showed significantly higher scores in the day wetting children (cases/controls: factor I 6.4/1.0, F $=8 \cdot 4, \mathrm{P}<0.01$, factor II $4 \cdot 5 / 1 \cdot 3, F=11 \cdot 3, P<0 \cdot 01$, factor III $6 \cdot 3 / 3 \cdot 7, \quad F=4 \cdot 1, P<0 \cdot 05$, factor IV $6 \cdot 0 / 2 \cdot 1$, $\mathrm{F}=9.3, \mathrm{P}<0.01$, factor $\mathrm{V}-2.6 /-0.4, \mathrm{~F}=9 \cdot 1$, $\mathbf{P}<0.01)$.

\section{Comments}

The two groups of children with daytime wetting were typical in terms of age distribution and the predominance of girls. Their fairly small maximum functional bladder capacities and the excess of behavioural problems at home and at school were also characteristic of diurnal enuresis. ${ }^{12}$

In view of the fact that imipramine relieves nocturnal enuresis, while the drug is being taken, ${ }^{4}$ it is surprising that we did not find it to affect daytime wetting significantly. It could be argued that since the pharmacokinetics of the drug vary considerably with different patients, larger doses might have been more effective for some children. Because cases were randomly assigned to treatment groups it was possible to use analysis of covariance on looking at the results. ${ }^{5}$ Yet no significant differences appeared when age, gender, and the various measures of psychological disturbance were allowed for.

Six of the children became reliably dry during the treatment trial, and most others had considerably

Tabie Average wetness score and average number of dry days, before treatment, on smaller dose (25 mg), on larger dose $(50 \mathrm{mg})$, and on follow-up

\begin{tabular}{|c|c|c|c|c|c|c|c|c|}
\hline \multirow[t]{2}{*}{ Group } & \multicolumn{4}{|c|}{ Average wetness score in previous 4 weeks } & \multicolumn{4}{|c|}{ Average number of dry days in previous 4 weeks } \\
\hline & $\begin{array}{l}\text { Before } \\
\text { treatment }\end{array}$ & $\begin{array}{l}\text { On smaller } \\
\text { dose }\end{array}$ & $\begin{array}{l}\text { On larger } \\
\text { dose }\end{array}$ & $\begin{array}{l}6 \text { month } \\
\text { follow-up }\end{array}$ & $\begin{array}{l}\text { Before } \\
\text { treatment }\end{array}$ & $\begin{array}{l}\text { On smaller } \\
\text { dose }\end{array}$ & $\begin{array}{l}\text { On larger } \\
\text { dise }\end{array}$ & $\begin{array}{l}6 \text { month } \\
\text { follow-up }\end{array}$ \\
\hline $\begin{array}{l}\text { Imipramine }(n=14) \\
\text { Placebo }(n=13)\end{array}$ & $\begin{array}{l}40 \\
36\end{array}$ & $\begin{array}{l}28 \\
27\end{array}$ & $\begin{array}{l}21 \\
26\end{array}$ & $\begin{array}{l}20 \\
30\end{array}$ & $\begin{array}{l}4 \\
6\end{array}$ & $\begin{array}{r}9 \\
12\end{array}$ & $\begin{array}{l}11 \\
15\end{array}$ & $\begin{array}{r}10 \\
9\end{array}$ \\
\hline
\end{tabular}


less wetness. This overall improvement is presumably explained by placebo effect and spontaneous remission rate. The failure of maximum bladder capacities to show any substantial increase corresponding to this improvement is further evidence of the unsatisfactory nature of this measure. ${ }^{36}$

Our trial suggests that imipramine, which is potentially dangerous because of the risks of accidental or deliberate overdose, should not be used for the treatment of children with diurnal enuresis.

We thank Ciba-Geigy for supporting this trial, and Mrs Wendy Pearson for assistance.

\section{References}

1 Berg I, Fielding D, Meadow R. Psychiatric disturbance, urgency, and bacteriuria in children with day and night wetting. Arch Dis Child 1977; 52: 651-7.
2 Berg I. Day wetting in children. J Child Psychol Psychiatry 1979; 20: 167-73.

3 Fielding D. The response of day and night wetting children and children who wet only at night to retention control training and the enuresis alarm. Behav Res Ther $1980 ; 18$ : 305-17.

4 Shaffer D. Enuresis. In: Rutter M, Hersov L, eds. Child psychiatry: modern approaches. Oxford: Blackwell, 1977: 599-600.

5 Huitema B C. The analysis of covariance and alternatives. New York: Wiley, 1980.

6 Berg I, Forsythe I, McGuire R. Response of bedwetting to the enuresis alarm. Influence of psychiatric disturbance and maximum functional bladder capacity. Arch Dis Child 1982; 57: 394-6.

Correspondence to Professor S R Meadow, Department of Paediatrics and Child Health, St James's University Hospital, Clinical Sciences Building, Beckett Street, Leeds LS9 7TF.

Received 12 May 1982

\title{
Familial benign copper deficiency
}

\author{
K MÉHES AND EVA PETROVICZ \\ Department of Paediatrics, County Hospital, Györ, Hungary
}

\begin{abstract}
SUMMARY Hypocupraemia with normal caeruloplasmin levels was found in a 21-month-old boy admitted to hospital because of repeated seizures and failure to thrive. He had blonde curly hair, spurring of the femora and tibiae, and mild anaemia, but his mental development, electroencephalogram, and structure of the hair on microscopical examination were normal. There was a general improvement in his condition with supplements of oral copper but as soon as these were reduced or stopped hypocupraemia and seizures resumed. Family investigation showed copper deficiency with mild symptoms in the mother and the maternal uncle. The pedigree suggests possible autosomal dominant or $\mathrm{X}$-linked dominant transmission.
\end{abstract}

Although several conditions leading to sporadic copper deficiency have been described, only two diseases, Wilson's hepatolenticular degeneration and Menkes's kinky-hair syndrome, are regarded as inherited abnormalities of copper metabolism. ${ }^{1}$

We report on what is perhaps a new form of familial hypocupraemia.

\section{Case report}

The propositus, birthweight $2.95 \mathrm{~kg}$, had a normal delivery and no perinatal complications. At age 6 months he was admitted to hospital because of a seizure and subsequent hypotonia. On admission there were no abnormal physical, neurological, or biochemical findings except for moderate anaemia. Serum copper level was not determined. As there were no symptoms he was discharged 6 days later.

During the next year, although his psychomotor development was good, weight gain was poor and he had frequent infections.

At age 21 months he was referred to our department because of seizures and hypotonic attacks. On admission his weight was below the 3rd centile, but height and head circumference were between the 10 th and 25 th centiles. His appearance was characteristic with a broad nasal bridge, Cupid's bow upper lip, and blonde curly hair (Fig. 1). The skin on his face was moderately seborrhoeic. Muscle tone, mental development, electroencephalogram, and eyes were normal. Radiological skeletal survey showed broadening and spurring of the femora and tibiae. Skeletal age corresponded to the chronological age. On microscopical examination the child's hair showed normal structure.

Levels of serum glucose, electrolytes, $\mathrm{pH}$, calcium, magnesium, zinc, immunoglobulins, hepatic and renal function tests, urine analysis, blood and urine amino-acid chromatography, glycosaminoglycan excretion were all normal. Stool bacteriology 